Cell Research (1993),3, 121-130

\title{
Fluorescent vital staining of plant sexual cell nuclei with DNA-specific fluorochromes and its application in ga- metoplast fusion
}

\author{
YANG Hongyuan, XINLI WU, YONGSheng MO, \\ CHANG ZHOU
}

Department of Biology, Wuhan University, Wuhan 430072, China

\begin{abstract}
DNA-binding fluorochromes are often used for vital staining of plant cell nuclei. However, it is not always sure whether the cells after staining still remain in living state. We chose several criteria to estimate the validity of real vital staining for sexual cell nuclei. These were: the cytoplasmic streaming in pollen tubes whose nuclei were stained, the simultaneous visualization of fluorochromatic reaction and nucleus staining in isolated generative cells, and the capability of isolated, prestained generative or sperm cells to fuse with other protoplasts. The results confirmed that 4,6-diamidino-2-phenylindole (DAPI), Hoechst 33258 and mithramycin could be used as real vital stains, though their efficiency varied from case to case; among them DAPI showed best effect. The fluorescent vital staining technique offered a useful means foridentification and selection of heterokaryons in gametoplast manipulation studies.
\end{abstract}

Key words: fluorescent vital staining, DNA-specific fluorochrome, generative cell, sperm cell, gametoplast fusion.

\section{INTRODUCTION}

Vital staining of nucleus is a useful method in plant cell culture and protoplast fusion studies. The DNA- specific fluorochromes such as 4,6-diamidino-2-phenylindole 
(DAPI), Hoechst 33258 (H33258) and mithramycin have usually been considered as vital mmlear stains. In regard to sexual cells, DAPI or mithramycin staining has been used for visualization of generative and vegetative nuclei in artificially germinated, fresh pollen tubes[1-4], and pollination with H33258 - or DAPI-prestained pollen has been used for tracing sperm nuclei in style or ovule tissues[5-8]. However, not in all these cases were direct evidences given for the real viability of stained cells at the moment of fluorescence observation; nor has there been reported such a vital nuclear staining technique adaptable to the in vitro fusion studies with gametoplast, i.e. isolated sperm or generative cell[9], as one of the fused partners.

The present investigation attempted to determine if the fluorescent staining of sexual cell nuclei was really capable of maintaining the viability of cells for further manipulation. Three criteria were adopted to estimate the viability of stained cells: (a) cytoplasmic streaming in pollen tubes whose generative and vegetative nuclei showed fluorescence of tested fluorochrome, (b) fluorochromatic reaction (FCR ) of isolated generative cells which were double-stained with fluorescein diacetate (FDA) and nuclear fluorochrome, and (c) the capability of fusion of isolated, prestained gametoplasts with other protoplasts.

\section{MATERIALS AND METHODS}

\section{Plant material, fluorochromes and microscopy}

Plant species used as materials were Zephyranthes grandiflora Lindle, Hemerocallis minor Mill. and Lycoris radiata Herb. Fluorescent dyes used were DAPI (Mannheim), H33258(Mannheim), mithramycin (Sigma) and FDA (Sigma). Microscopic observations were carried out with an Olympus NEW VANOX AHBS-514 research microscope or an Olympus IMT-2 inverted microscope, both equipped with epifluorescence attachments, U excitation for DA PI and H33258, B excitation for mithramycin and FDA.

\section{Staining of nuclei in pollen tubes}

In one experiment, $Z$. grandiflora pollen was germinated in hanging drops of BK medium[10] containing $12 \%$ sucrose. After incubation at $25{ }^{\circ} \mathrm{C}$ for $3 \mathrm{~h}$, when the vegetative nucleus and generative cell had been located in the pollen tubes, the original drops were absorbed with a piece of filter paper and replaced by new drops of fluorochrome-supplemented medium. Then samples were monitored at intervals to examine the nuclear fluorescence and cytoplasmic streaming in the same pollen tubes.

In another experiment, the pollen was stained prior to germination in fluorochrome-containing BK medium in Petri dishes. Samples were collected periodically and washed thoroughly with fluorochrome-free medium. Then the prestained pollen was cultured in hanging drops for $3 \mathrm{~h}$ and the pollen tubes thus germinated were examined for viewing the nucleus fluorescence and cytoplasmic streaming.

\section{Staining of isolated generative cells}

Generative cells of $H$. minor were isolated in quantities by a "weak enzymatic method" [11]: The pollen was incubated in 5\% sucrose solution containing $0.1 \%$ cellulase (Onozuka R-10) and $0.1 \%$ pectinase (Serva) at $25^{\circ} \mathrm{C}$ for $20-25 \mathrm{~min}$ to release the generative cells. After filtration and centrifugation, the purified generative cells were stained with nuclear fluorochrome $(20 \mu \mathrm{g} / \mathrm{ml}$ in 
19\% sucrose solution) for $20 \mathrm{~min}$. Then FDA stock solution was added to a final concentration of $10 \mu \mathrm{g} / \mathrm{ml}$. Through centrifugation, the precipitated generative cells were observed to determine the nucleus staining and FCR simultaneously.

\section{Fusion of isolated, prestained gametoplasts with other protoplasts}

Two sets of experiments were carried out. In the first experiment, isolated generative cells were fused with petal protoplasts in L. radiata. The generative cells were isolated by a "two-step osmotic shock method"[12] and stained with $5 \mu \mathrm{g} / \mathrm{ml}$ DAPI for $30 \mathrm{~min}$, followed by thorough washing with fluorochrome-free solution. The petal protoplasts were prepared by maceration of petal strips with $1 \%$ cellulase and $1 \%$ pectinase solution at $28^{\circ} \mathrm{C}$ for $6 \mathrm{~h}$. Fusion was induced by polyethylene glycol (PEG, M.W. 6000) according to a "small-scale fusion procedure” [13].

The second experiment dealt with fusion between isolated sperm cells and microspore protoplasts in H. minor. The sperms were isolated by an in vivo/ in vitro technique[14]: Cut styles of 1 $\mathrm{cm}$ were inserted into BK medium containing $8 \%$ sucrose. After $20 \mathrm{~h}$ of pollination, when sperm cells were observed in the pollen tube tips growing out from the cub ends, the styles were transferred to BK medium containing $0.5 \%$ cellulase, $0.5 \%$ pectinase and $4 \%$ sucrose to release sperms. The isolated sperms were then stained with $10 \mu \mathrm{g} / \mathrm{ml}$ DAPI for $20 \mathrm{~min}$. The microspore protoplasts were prepared basically according to the method developed by Zhou[15]. Fusion was induced by the "small-scale fusion procedure" [13].

\section{RESULTS}

\section{Visualization of stained nuclei in living pollen tubes}

The vegetative nucleus in pollen tubes began to show fluorescence after stained with mithramycin $(20$ or $50 \mu \mathrm{g} / \mathrm{ml}$ ) for $30 \mathrm{~min}$, whereas the generative nucleus fluoresced much later and weaker, usually after $90 \mathrm{~min}$ of staining (Fig 1 and 2). Cytoplasmic streaming was evident in all the tubes with fluorescing nuclei. In many cases the vegetative nucleus changing its shape and moving slowly along the tubes was observed. Supplementation of dimethyl sulphoxide (DMSO, 2 or 5\%) into the medium could enhance the penetration of fluorochrome, but did not show effect on the relative fluorescence intensity of vegetative and generative nuclei (Fig 3). When pollen prestained with mithramycin $(20 \mu \mathrm{g} / \mathrm{ml})$ was germinated in dye-free medium, the pollen tubes grew well with vigorous cytoplasmic streaming. Prestaining for 15 min did not result in nucleus fluorescence; $30-45$ rain prestaining only labeled vegetative nuclei; 60 min prestaining could label generative nuclei as well.

Direct pollen tube staining or, alternatively, pollen prestaining with DAPI (20 $\mu \mathrm{g} / \mathrm{ml}$ ) showed similar results of simultaneous nucleus fluorescence and cytoplasmic streaming in the pollen tubes. However, there were two distinct points different from mithramycin staining. First, the fluorescence of DAPI maintained much longer than that of mithramycin which faded rapidly under excitation. Second, in the case of DAPI staining, the generative nucleus usually fluoresced brighter than the vegetative one did (Fig 4). This was considered normal since the DNA of generative nucleus is usually more condensed than that of vegetative nucleus.

H33258 failed to work in either pollen tube staining or pollen prestaining. Attempts to improve its effect including raising the dye concentration (from 20 to 200 $\mu \mathrm{g} / \mathrm{ml}$ ) or the $\mathrm{pH}$ value of the medium (from $\mathrm{pH} 7$ to 10 ) as well as supplementation 
Fluorescent vital staining of plant sexual cell nuclei

of DMSO (2 or 5\%) could not lead to positive results (Fig 5 and 6). The nuclei did not fluoresce unless the cytoplasmic streaming had ceased or the nuclei had been released from bursted tubes into the medium.

\section{Visualization of stained nucleus in isolated, living generative cells}

Isolated generative cells of $H$. minor sequentially stained with DAPI $(20 \mu \mathrm{g} / \mathrm{ml})$ and FDA $(10 \mu \mathrm{g} / \mathrm{ml})$ showed simultaneous nucleus fluorescence and FCR on observation with $U$ and $B$ excitation respectively (Fig 7-10). Of the 124 generative cells demonstrating FCR, 115 cells exhibited also DAPI fluorescence, denoting that 92.7\% of the viable cells allowed DAPI staining. Alternatively, of the 240 generative cells demonstrating DAPI fluorescence, 213 cells showed FCR, indicating that $88.8 \%$ of the DAPI-stained cells were viable. By any means of calculation, a high efficiency of vital staining was confirmed.

Generative cells could be double-stained similarly with H33258 $(20 \mu \mathrm{g} / \mathrm{ml})$ and FDA $(10 \mu \mathrm{g} / \mathrm{ml})$. Here, the nucleus fluorescence was somewhat weaker than that stained with DAPI under the same condition of dye concentration and staining duration (Fig 11, 12).

Double staining did not succeed with mithramycin $(20 \mu \mathrm{g} / \mathrm{ml})$. It was not clear yet why negative results were obtained. One possible reason was that mithramycin molecules could hardly penetrate the plasma membrane of generative cells, since in the experiments mentioned above, the staining process of generative cell in pollen tubes with mithramycin was very slow and weak. Another possibility was that mithramycin fluorescence and FCR were viewed with the same B excitation, that caused a masking of the former by the latter.

\section{Visualization of prestained gametoplast nuclei during protoplast fusion}

In the experiment on fusion between generative cells and petal protoplasts in $L$. radiata, the generative cells were prestained with DAPI before fusion while the petal protoplasts were unstained. During the fusion process, bright-field observation could distinguish the outline of a generative cell by its yellow-brown pigmentation of the cytoplasm from the petal protoplast which was characterized by red-colored anthocyanin in the vacuole (Fig 13). Fluorescence observation on the same specimen could detect a strongly fluorescing generative nucleus in the fusion products. The petal protoplast nucleus in the fusion products sometimes also showed faint fluorescence, though the nucleus of unfused petal protoplasts never did so (Fig 14).

In the experiment dealt with fusion between sperm cells and microspore protoplasts in $H$. minor, similar behavior was observed. The sperm nuclei prestained with DAPI showed bright fluorescence whereas the unstained microspore protoplast nuclei did not (Fig 15 and 16). When a sperm cell had adhered to a microspore protoplast, still only the former demonstrated fluorescence (Fig 17 and 18). After uptake of a sperm by a petal protoplast, both nuclei were not discernible by bright- 
field observation (Fig 19), but by fluorescence observation the sperm nucleus could be detected and sometimes the microspore nucleus as well (Fig 20).

\section{DISCUSSION}

Though DNA-specific fluorochromes have often been used to detect the nucleus of fresh cells, there have been reports concerning limitations in their utilization. For instance, H33258 can not well stain the living protoplasts except in the presence of Triton X-100 [16]; so are DAPI and ethidium bromide[17]. H33342, an analog of $\mathrm{H} 33258$, can stain the living protoplasts only when the medium is adjusied to $\mathrm{pH} 10[18,19]$. In extreme cases, H33258[20] and propidium iodide[21] are used as probes for dead cells instead of living ones. Even in recent years, there has been a dilemma about whether DAPI-stained cells are "alive, or dead, or a bit of both" (see letters in Trends in Genetics, Vol 5, No. 9, 1989). Therefore, it is now still worthwhile to reexamine this problem.

If we consider the concept of "vital staining" as a staining of real living cells, we should exclude such cases as the formerly living cells are dying at the moment of observation. Since DNA-binding fluorochromes stain dead cells much easier than living ones, such possibility should always be kept in mind. As an example, when using H33258-prestained pollen for semi-vitro pollination in Nicotiana alata, Mulcahy and Mulcahy (1986) saw fluorescing sperm nuclei in the pollen tubes growing along the style and beyond the stylar cut ends. However, they noticed that the nuclei were visible only after cytoplasmic streaming in the tube had ceased[6]. Our present observation on H33258-stained pollen tubes confirmed this point.

In this paper we used three criteria to estimate the validity of fluorescent vital staining of sexual cell nuclei. Judged by cytoplasmic streaming in pollen tubes, both DAPI and mithramycin were confirmed to have the ability of vital staining (though mithramycin stained the generative nucleus less prominantly), but H33258 did not. When FCR was used as a criterion in an isolated generative cell system, the nuclei were vitally stained by either DAPI or H33258, but not by mithramycin. The success of simultaneous visualization of nucleus fluorescence and FCR in isolated generative cells was in contrast to such cases as in pollen grains[2] and aleurone protoplasts[21], where nucleus fluorescence could not be visualized together with FCR. The last evidence of vital staining was the ability of stained gametoplasts to fuse with other protoplasts as has been suggested[22]. Since the results from the first two experiments had shown that DAPI was the most superior one among the three tested fluorochromes, we used only DAPI for gametoplast fusion experiments, and positive results were obtained. Thus, through three sets of experiments we, can conclude that for the tested fluorochromes, DAPI has its really vital staining ability to a certain degree.

Recently there have been attempts to utilize isolated gametoplasts in plant biotechnology[23-26]. With regard to fusion studies, there were reports on fusion of 
generative cell with generative cell[27, 28], pollen protoplast[27] and somatic protoplast[28]. In all these cases homokaryons or heterkaryons have been obtained. Kranz et al. have succeeded in fusion between isolated single sperm and egg cell in maize and cultured the fusion products to multicelluar structures[29]. In the present paper, DAPI-labeled gametoplasts were fused with petal or microspore protoplasts. The fluorescence of gametoplast nuclei could be clearly visualized in the heterokaryon. It is interesing that sometimes the unstained somatic or microspore protoplast nucleus in the fusion products showed fluorescence too. This can be interpreted as a consequence of diffusion of the fluorochrome molecules from the donor nucleus during the fusion process. Similarly, Williams and Keijzer noticed that DAPI-labeled pollen tube could stain nuclei of female tissues after its entering the ovule and discharging into the embryo sac[8]. To sum up, the fluorescence vital staining technique is useful for tracing gametoplast nucleus in fusion process and for selecting desirable heterokaryons in gameto-gametic or gameto-somatic hybridization studies.

\section{ACKNOWLEDGEMENT}

This study is supported by the National Natural Sciences Foundation of China.

\section{REFERENCES}

[1] Heslop-Harrison J, Heslop-Harrison Y. The disposition of gamete and vegetative-cell nuclei in the extending pollen tubes of a grass species, Alopecurus pratensis L. Acta Bot Neerl 1984; 33:131-4.

[2] Coleman AW, Goff LJ. Applications of fluorochromes to pollen biology. I. Mithramycin and 4, 6-diamidino-2-phenylindole (DAPI) as vital stains and for quantitation of nuclear DNA. Stain Technol 1985; 60:145-54.

[3] Hepher A, Sherman A, Gates P, Boulter D. Microinjection of gene vectors into pollen and ovaries as a potential means of transforming whole plants. In: Chapman GP, Mantell SH, Daniels RW (eds) The experimental manipulation of ovule tissues. Longman, New York London, 1985; 52-75.

[4] Heslop-Harrison J, Heslop-Harrison J S, Heslop-Harrison Y. The comportment of the vegetative nucleus and generative cell in the pollen and pollen tubes of Helleborus foetidus L. Ann Bot 1986; 58:1-12.

[5] Hough T, Bernharbt P, Knox RB, Williams EG. Applications of fluorochromes to pollen biology. II. The DNA probe ethidium bromide and Hoechst 33258 in conjunction with the callose-specific aniline blue fluorochrome: Stain Technol 1985; 60:155-62.

[6] Mulcahy GB, Mulcahy DL. Use of vital dyes in conjunction with the semivitro technic for the detection of pollen tube sprem nuclei. Stain Technol 1986; 61:382-3.

[7] Keijzer C J, Reinder MC, Janson J, Tuyl J van. Tracing sperm cells in styles, ovaries and ovules of Lilium longiflorum after pollination with DAPI-stained pollen. In: Wilms H J, Keijzer CJ eds Plant sperm cells as tools for biotechnology. Pudoc, Wageniningen. 1988; 148-52.

[8] Williams MTM, Keijzer CJ. Tracing pollen nuclei in the ovary and ovule of Gasteria verrucosa (Mill.) H. Duval after pollination with DAPI - stained pollen. Sex Pl Reprod 1990; 3:219-24.

[9] Russell SD. Isolation of sperm cells from the pollen of Plumbago zeylanica. Plant physiol 1986; 81:317-9.

[10] Brewbaker JL, Kwack BH. The essential role of calcium ion in pollen germination and pollen tube growth. Am J Bot 1963; 50:859-65. 
[11] $\mathrm{Wu}$ XL, Zhou C. A comparative study on methods for isolation of generative cells in various angiosperm species. Acta Biol Exp Sin 1991; 24:15-23.

[12] Zhou C. Isolation and purification of generative cells from fresh pollen of Vicia faba L. Plant Cell Reports 1988; 7:107-10.

[13] Power JB, Chapman JV. Somatic hybridization of plants. In: Dixon RA (ed) Plant cell culture: a practical approach. IRL Press, Oxford Washington DC. 1985; 37-66.

[14] Shivanna KR, Xu H, Taylor P, Knox RB. Isolation of sperms from the pollen tubes of flowering plants during fertilization. Plant Physiol 1988; 87:647-50.

[15] Zhou C. Cell divisions in pollen protoplast culture of Hemeroeallis fulva L. Plant Sci 1989; 62:229-35.

[16] Meadows MG, Potrykus J. Hoechst 33258 as a vital stain for plant cell protoplasts. Plant Cell Reports 1981; 1:77-9.

[17] Reich T J, Iyer V N, Haffner M, Holbrook LA, Miki BL. The use of fluorescent dyes in the microinjection of alfalfa protoplasts. Can J Bot 1986; 64:1259-67.

[18] Puite KJ, Broake WRRT. DNA staining of fixed and non-fixed plant protoplasts for flow cytometry with Hoechst 33342. Plant Sci Lett 1983; 32:79-88.

[19] van der Valk HCPM, Blaas J, van Eck JW, Verhoeven HA. Vital DNA staining of agaroseembedded protoplasts and cell suspensions of Nicotiana plumbaginifolia. Plant Cell Reports 1988; 7:489-92.

[20] Singh NP, Stephens RE. A novel technique for viable cell determinations. Stain Technol 1986; 61:315-8.

[21] Huang CN, Cornejo M J, Bush DS, Jones RL. Estimating viability of plant protoplasts using double and single staining. Protoplasma 1986; 135:80-7.

[22] Cass DD, Fabi GC. Structure and properties of sperm cells isolated from the pollen of Zea mays. Can J Bot 1988; 66:819-25.

[23] Wilms HJ, Keijzer CJ (eds) Plant sperm cells as tools for biotechnology. Pudoc, Wageningen. 1988.

[24] Zhou C, Yang HY. Experimental manipulation of pollen protoplasts, sperms and generative cells. Acta Bot Sin 1989; 31:726-34.

[25] Theunis CH, Pierson ES, Cresti M. Isolation of male and female gametes in higher plants. Sex P1 Reprod 1991; 4:145-54.

[26] Yang HY, Zhou C. Experimental plant reproductive biology and reproductive cell manipulation in higher plants: now and he future. Am J Bot 1992; 79:354-63.

[27] Ueda K, Miyamoto Y, Tanaka I. Fusion studies of pollen protoplasts and generative cell protoplasts in Lilium longiflorum. Plant Sci 1990; 72:259-66.

[28] Wu XL, Zhou C. Fusion experiments of isolated generative cells in several angiosperm species. Acta Bot Sin 1991; 33:897-904.

[29] Kranz K, Bautor J, Lorz H. In vitro fertilization of single, isolated gametes of maize mediated by electrofusion. Sex P1 Repord 1991; 4:12-6.

Received 8-6-1992. Revised 11-1-1993. Accepted 17-2-1993. 

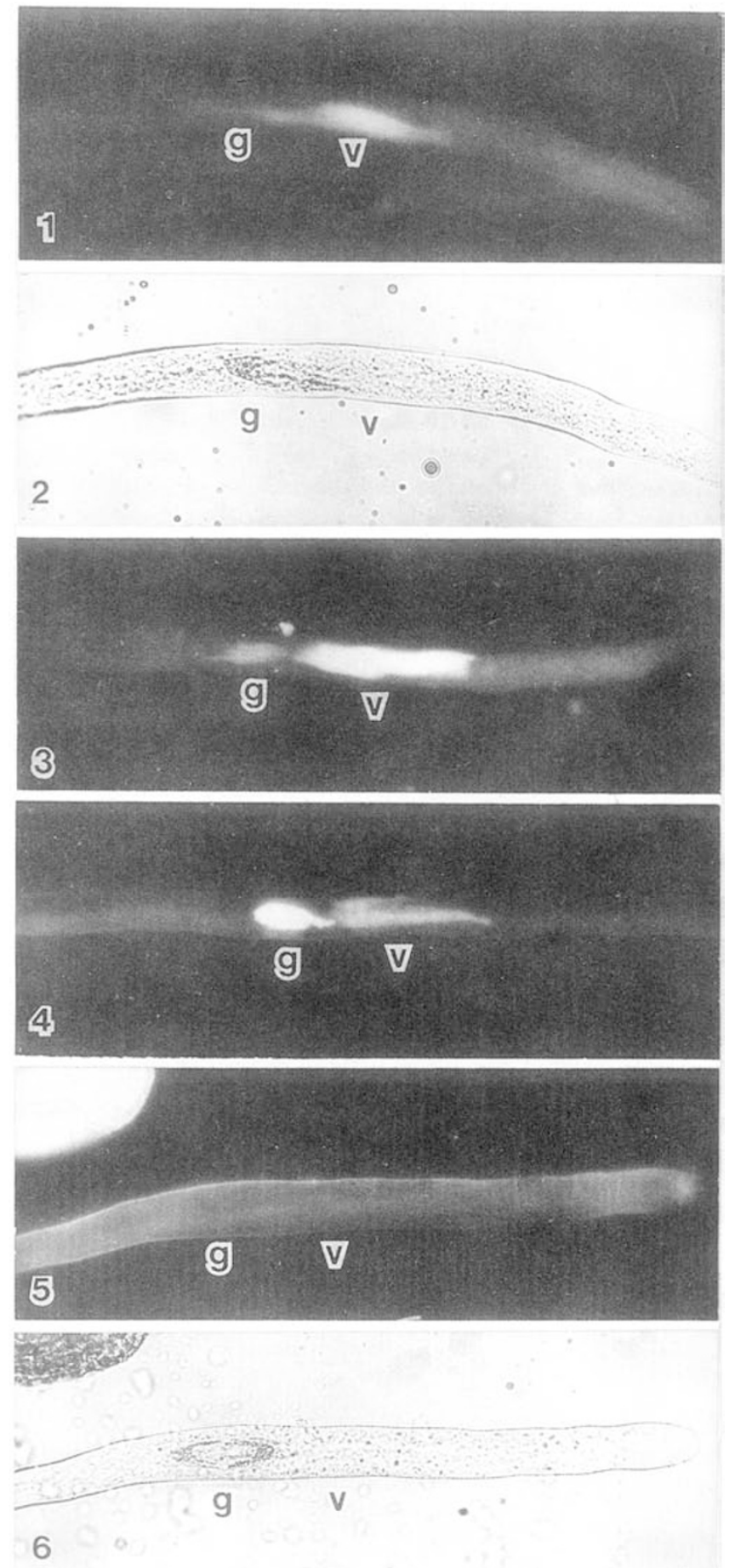

\section{Plate 1}

Fluorescence vital staining of pollen tube nuclei in $\mathrm{Z}$. graniflora. $\times 240$. g. Generative cell. v. Vegetative nucleus.

Fig 1. A pollen tube stained with $20 \mu \mathrm{g} / \mathrm{ml}$, mithramycin for 90 min. The vegetative nucleus fluoresces, but the generative nucleus does not yet.

Fig 2. Bright-field micrograph of the same pollen tube in Fig 1 , showing position of the generative cell.

Fig 3. A pollen tube stained with $20 \mu \mathrm{g} / \mathrm{ml}$ mithramycin in conjunction with $2 \%$ DMSO for $90 \mathrm{~min}$, showing fluorescence of both nuclei.

Fig 4. A pollen tube germinated from DAPIprestained pollen, showing the brightly fluorescing generative nucleus and the fainter vegetative nucleus.

Fig 5. A pollen tube germinated from pollen prestained with 20 $\mu \mathrm{g} / \mathrm{ml} \mathrm{H} 33258$ at $\mathrm{pH}$ 10 for $60 \mathrm{~min}$. The nuclei show no fluorescence.

Fig 6. Bright-field micrograph of the same pollen tube in Fig 5, showeing position of the generative cell. 
Yang HY, et al.
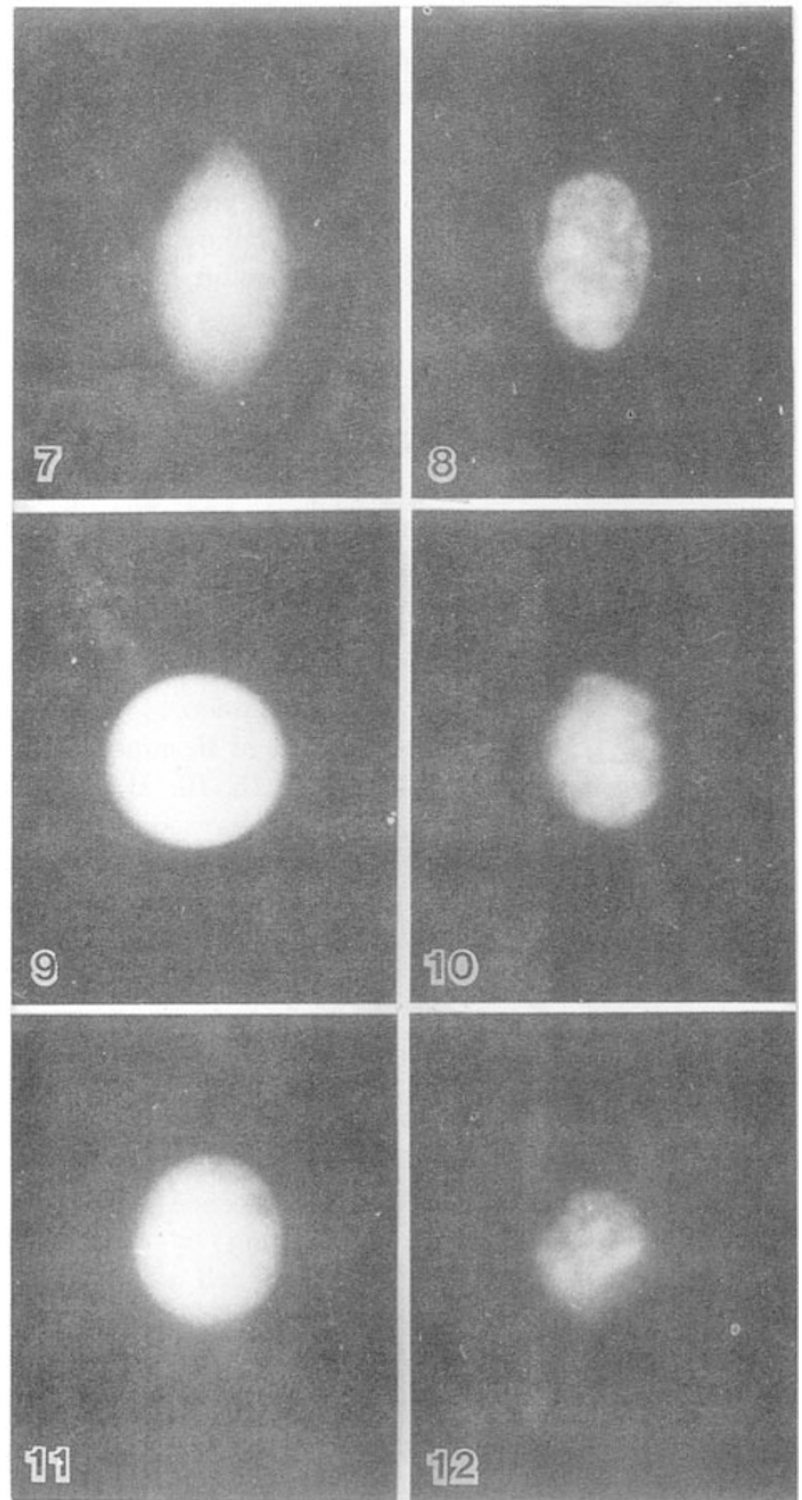

8
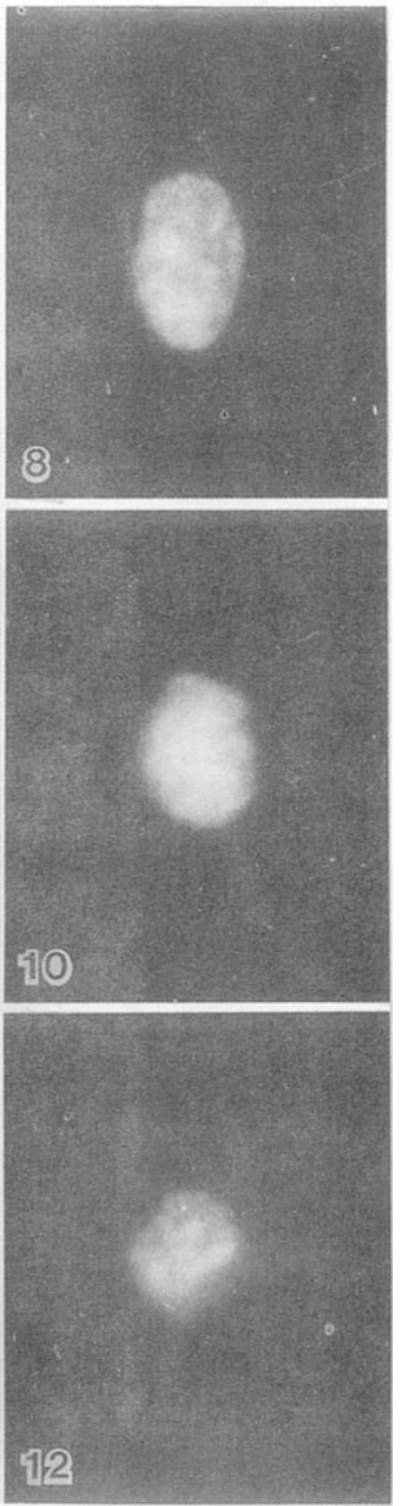

\section{Plate 2}

Fluorescence vital staining of isolated generative cells in $H$. minor. $\times 1000$.

Fig 7. FCR of an ellipsoidal generative cell stained with $10 \mu \mathrm{g} / \mathrm{ml}$ FDA.

Fig 8. The same cell shows fluorescence of its nucleus stained with 20 $\mu \mathrm{g} / \mathrm{ml}$ DAPI.

Fig 9.10. A spherical generative cell showing simultaneous FCR (Fig 9) and DAPI fluorescence (Fig 10).

Fig 11, 12. A generative cell showing simultaneous FCR (Fig 11) and H33258 fluorescence (Fig 12). 


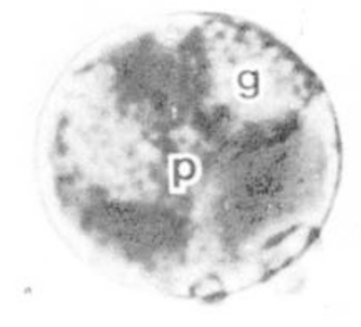

13

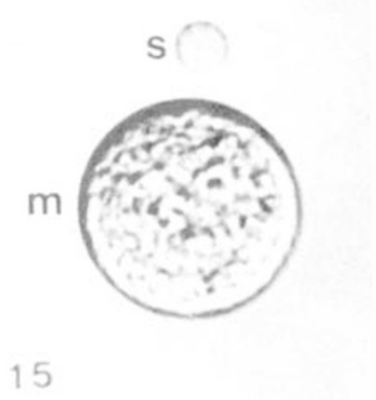

17
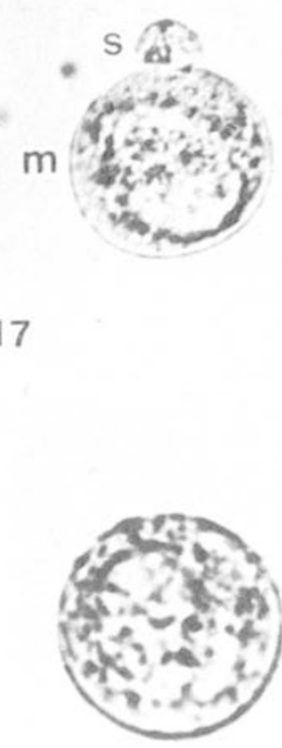

19
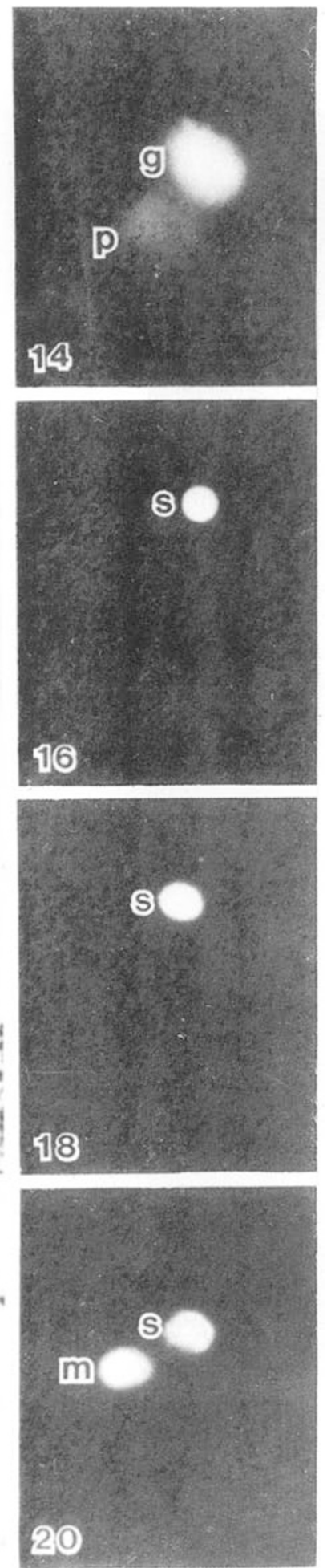

\section{Plate 3}

Detection of DAPI- prestained gametoplasts during protoplast fusion. g. Generative cell or its nucleus, m. Microspore protoplast or its nucleus, p. Petal protoplast or its nucleus, s. Sperm cells.

Fig 13. Fusion of an isolated, DAPI-prestained generative cell with a petal protoplast in L. radiata. $\times$ 1200.

Fig 14. Fluorescence micrograph of the same specimen, showing the brightly fluorescing generative nucleus and the fainter petal protoplast nucleus. $\times 1200$.

Fig 15-20. Fusion of isolated, DAPI -prestained sperm cells with microspore protoplast in $H$. minor. $\times 800$ Figs 15, 16. Bright-field and corresponding fluorescence micrographs of a sperm cell and a microspore protoplast prior to fusion. The sperm nucleus fluorescing brightly while the microspore nucleus not.

Fig 17, 18. Brightfield and corresponding fluorescence micrographs showing a fluorescing sperm cell adhering to a microspore protoplast. Fig 19, 20. Bright-field and corresponding fluores cence micrographs showing a heterokaryon, in which the sperm nucleus fluoresces brightly; the microspore nucleus also shows some fluorescence. 